\title{
Chromosome III
}
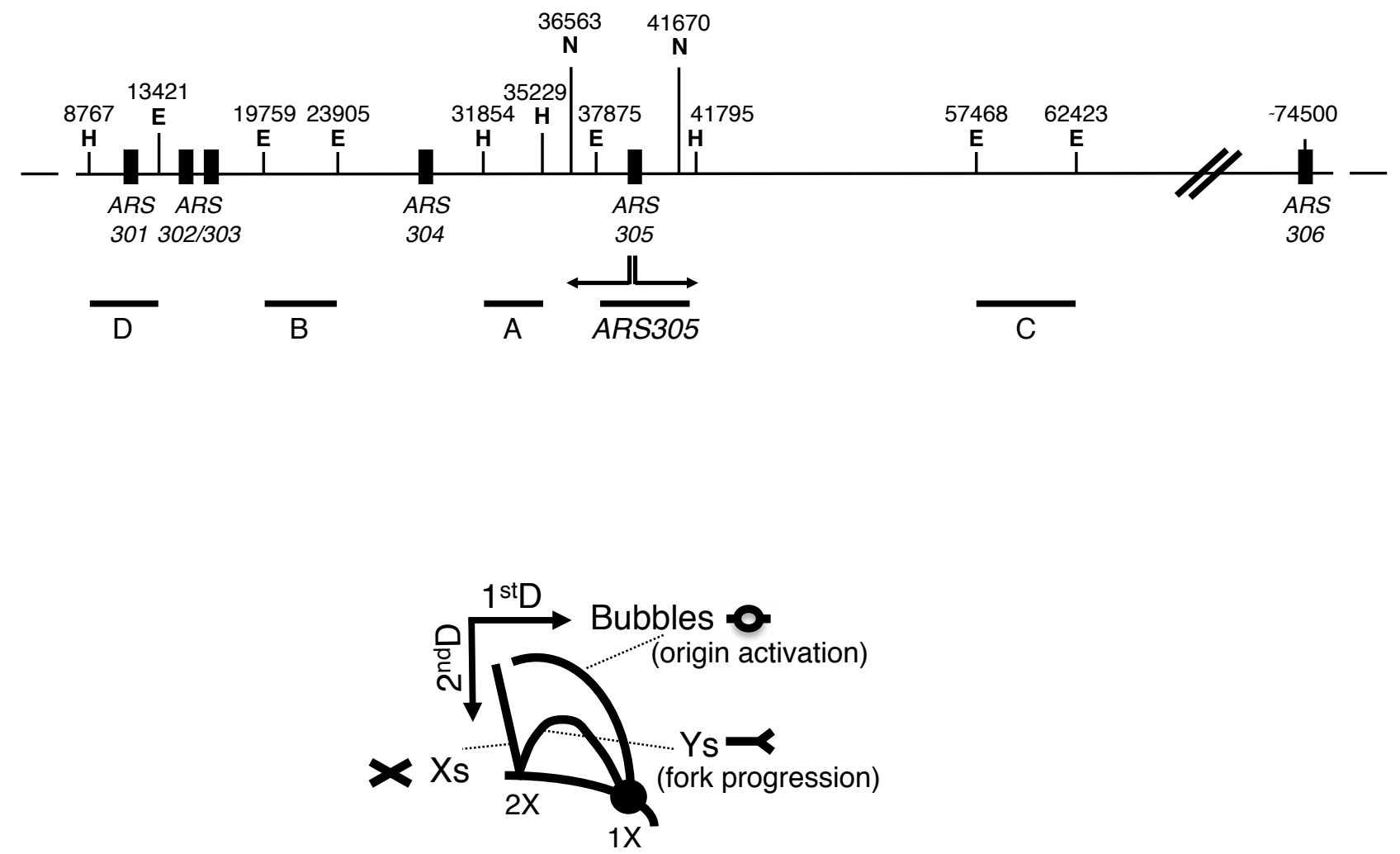


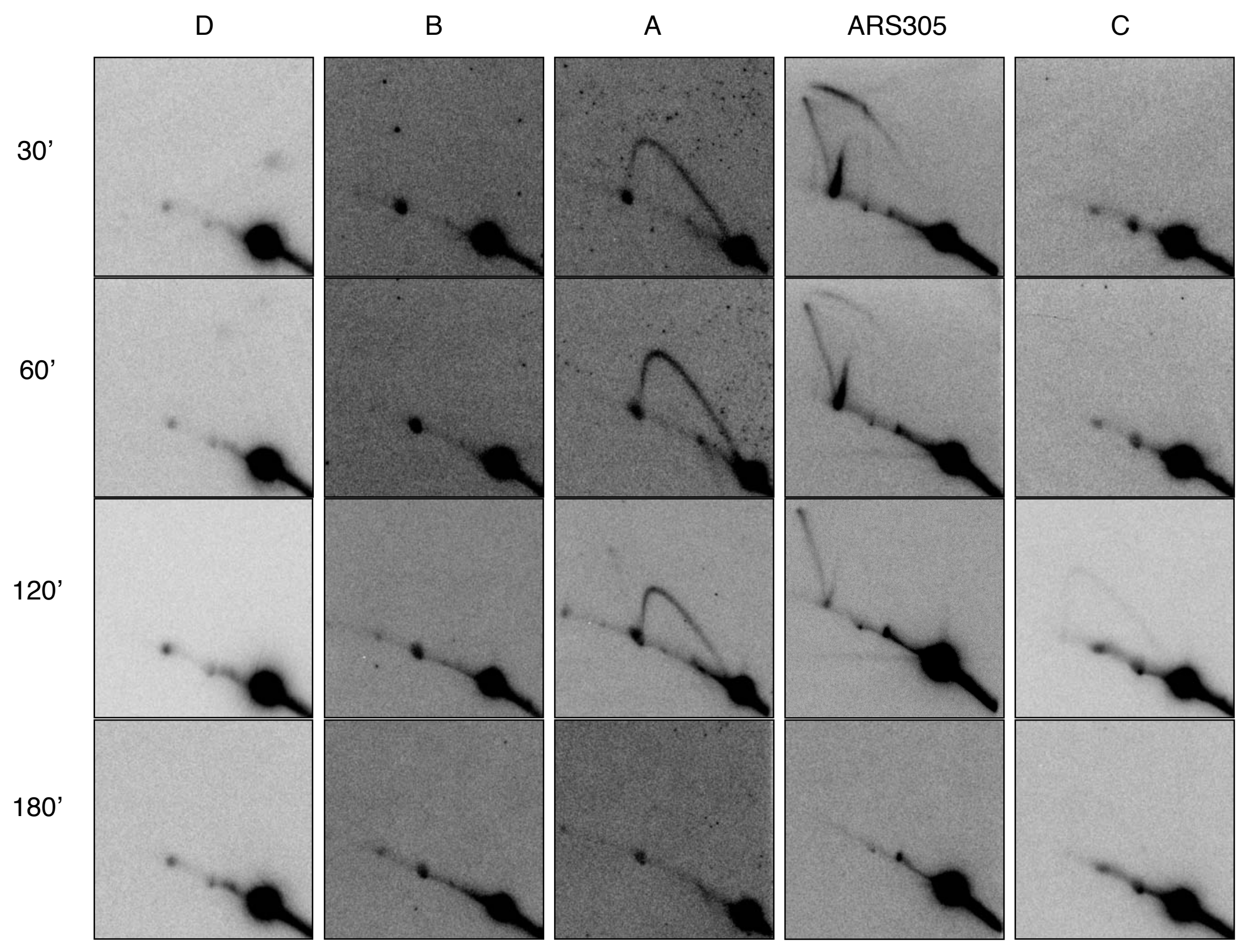




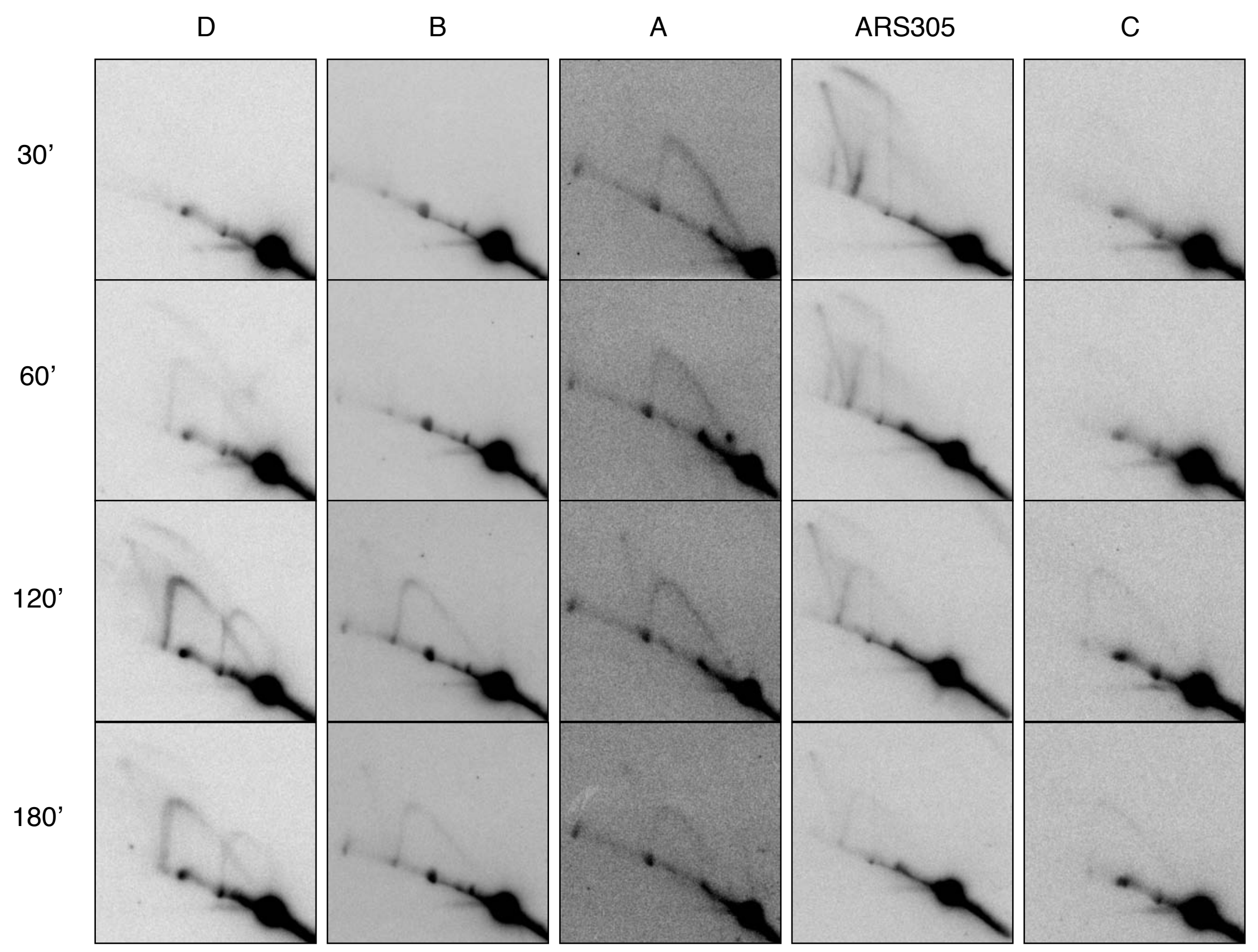




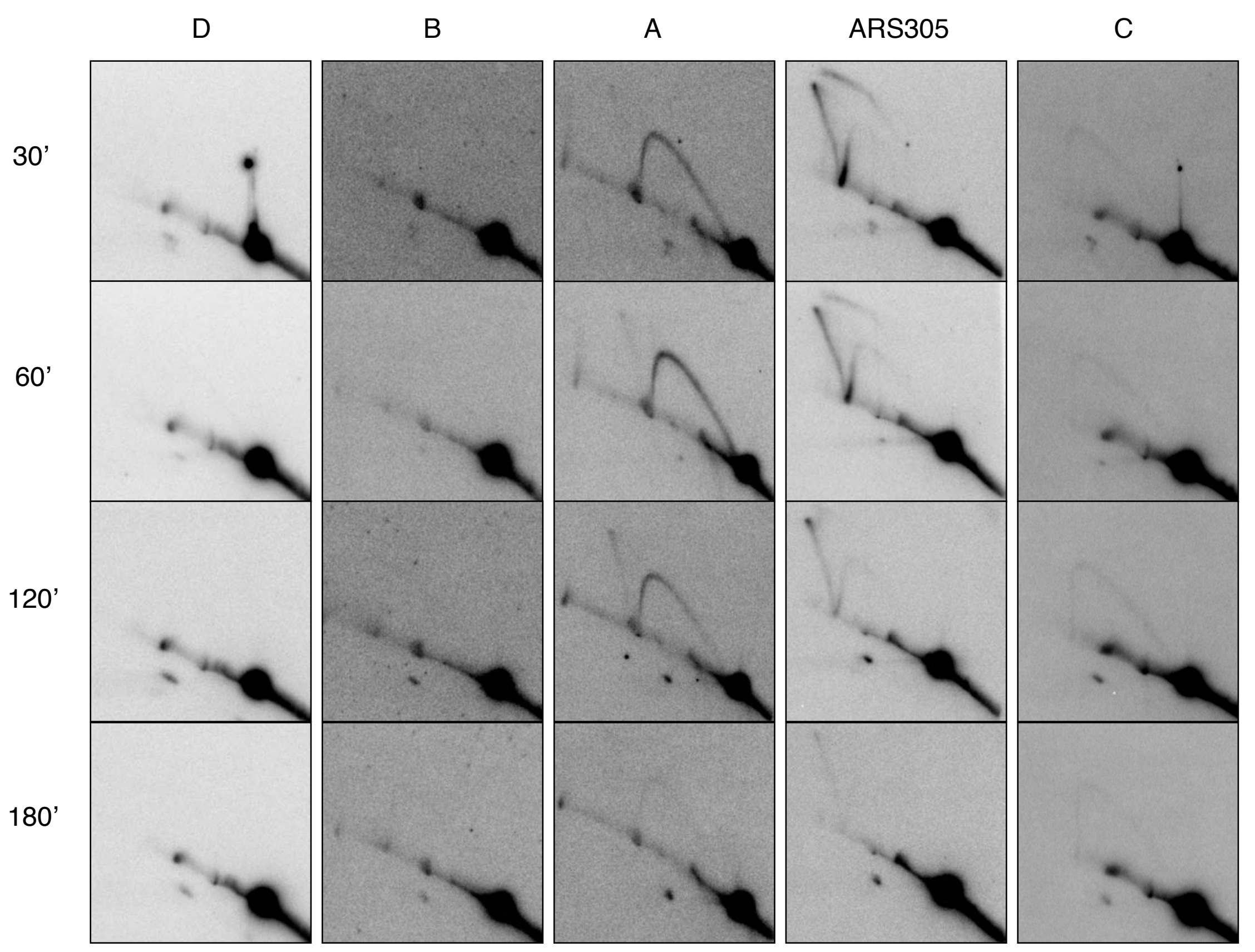




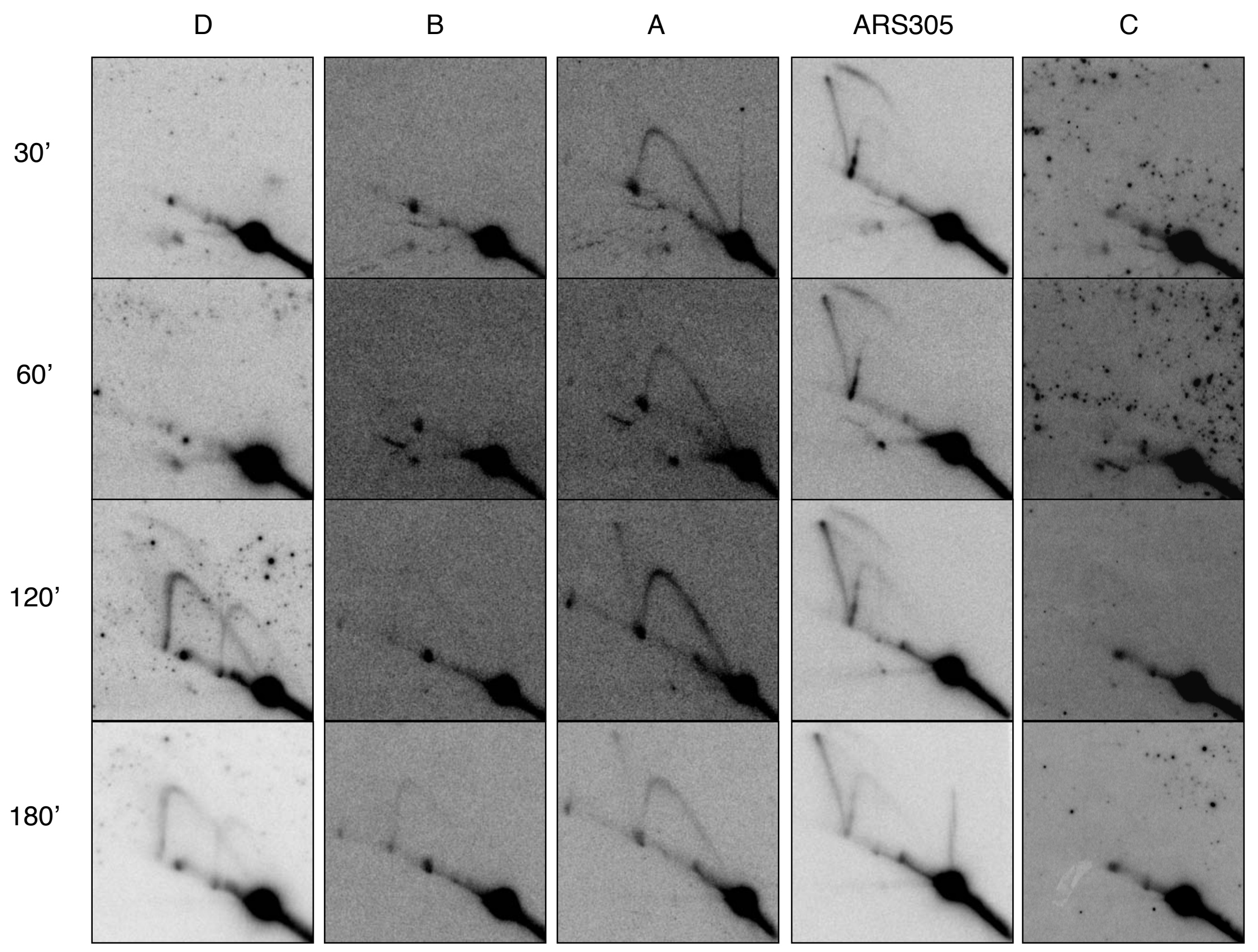




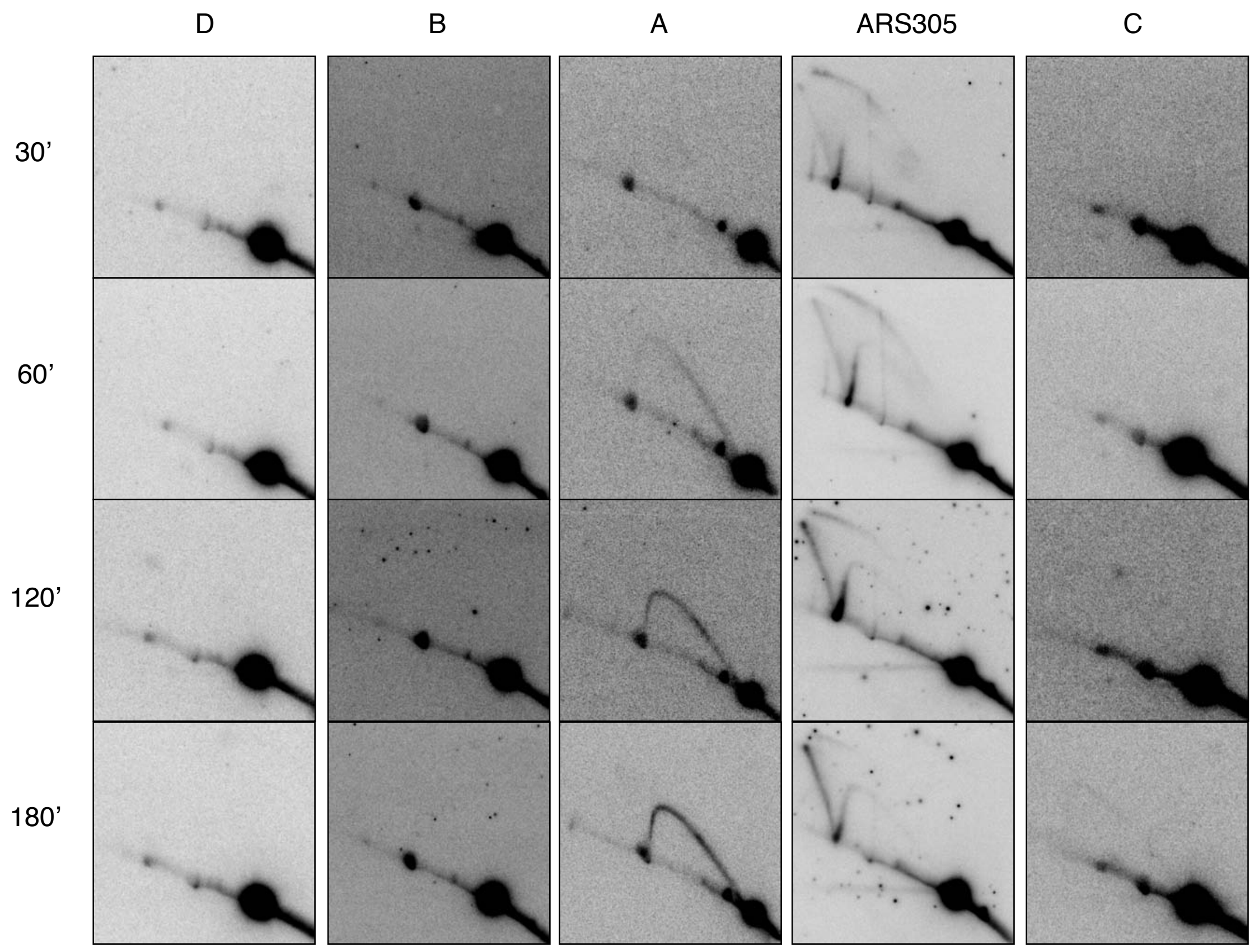




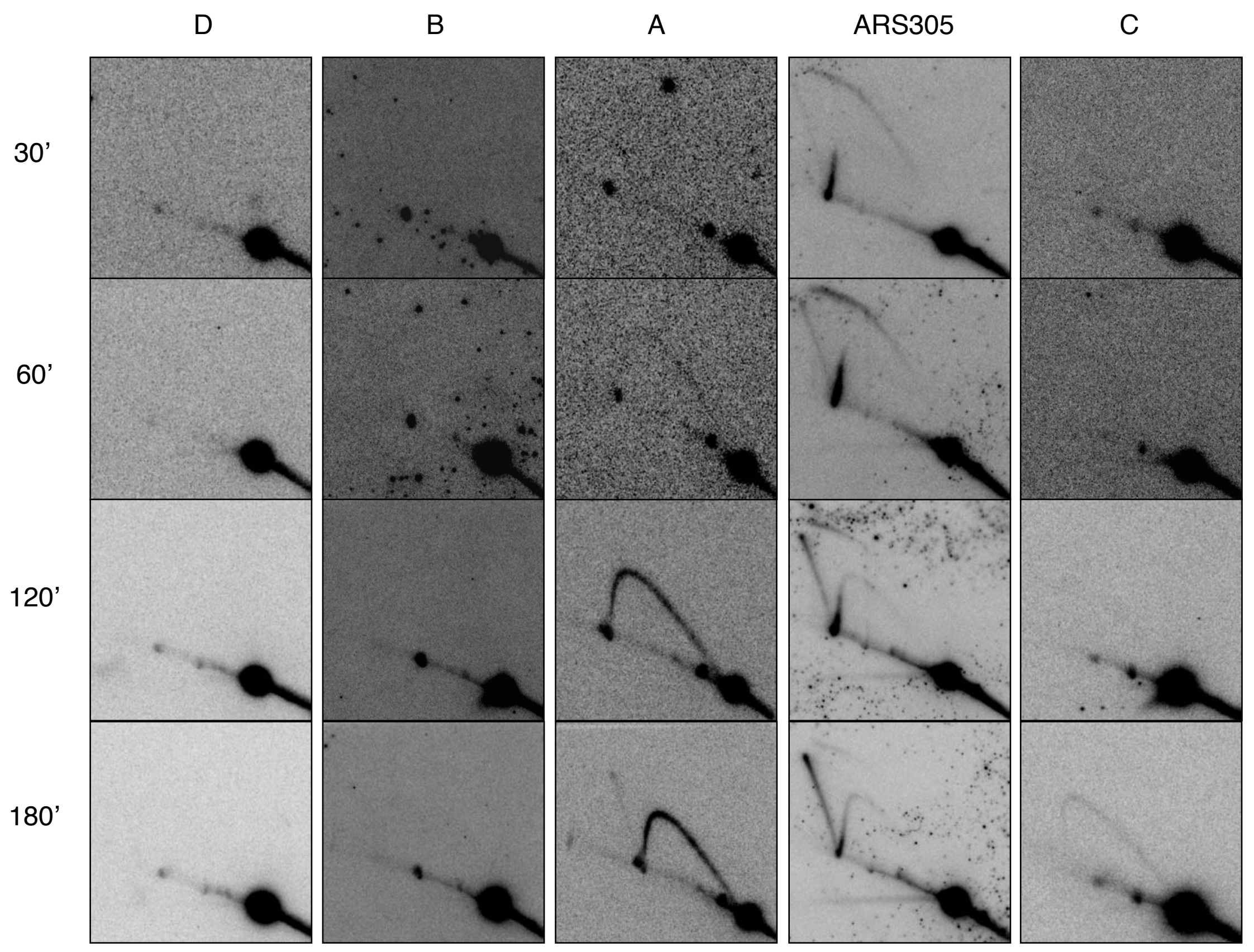




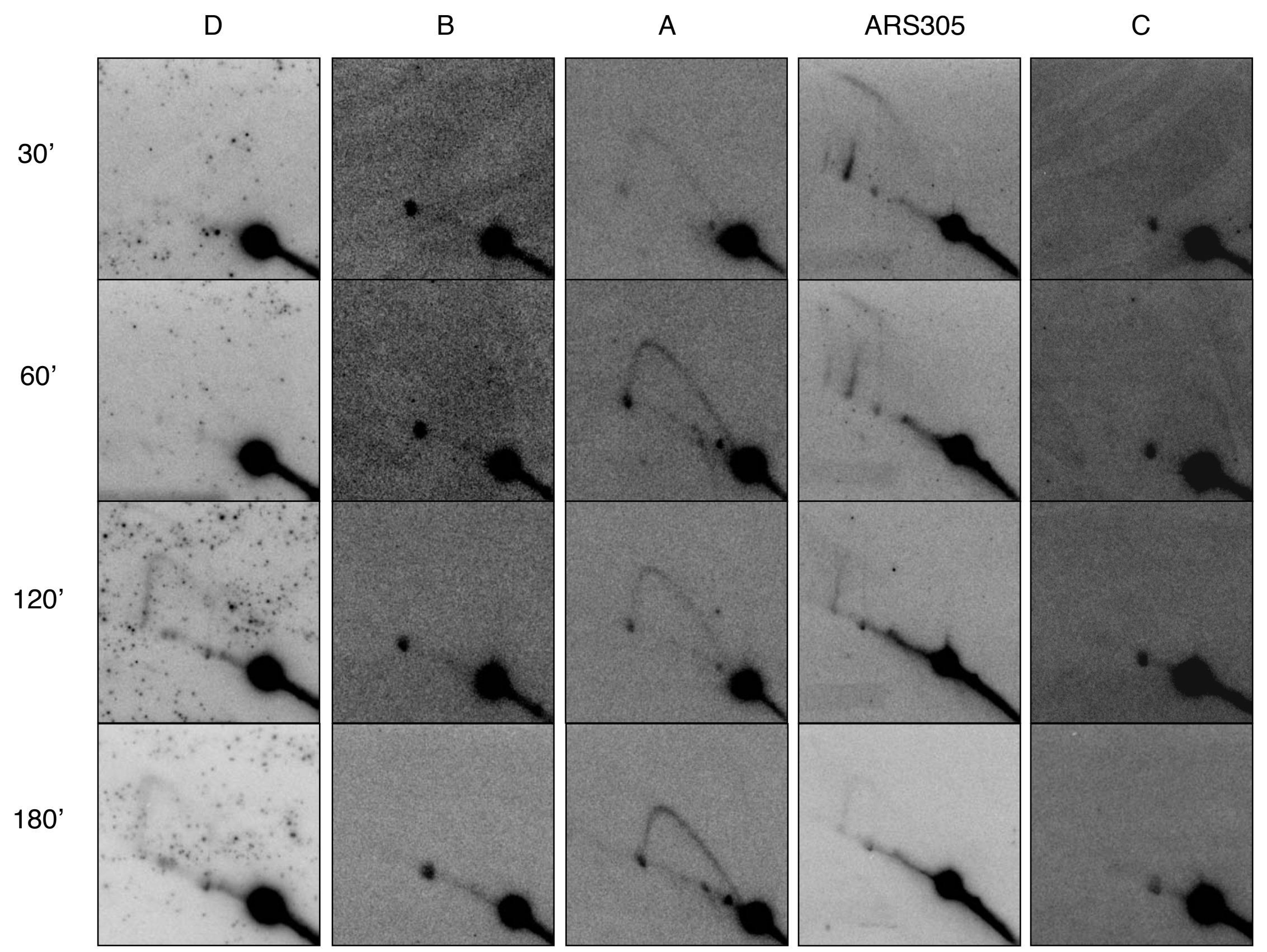


bmh1-280 bmh2 $\Delta$ rad53-K227A exo1 $\Delta$

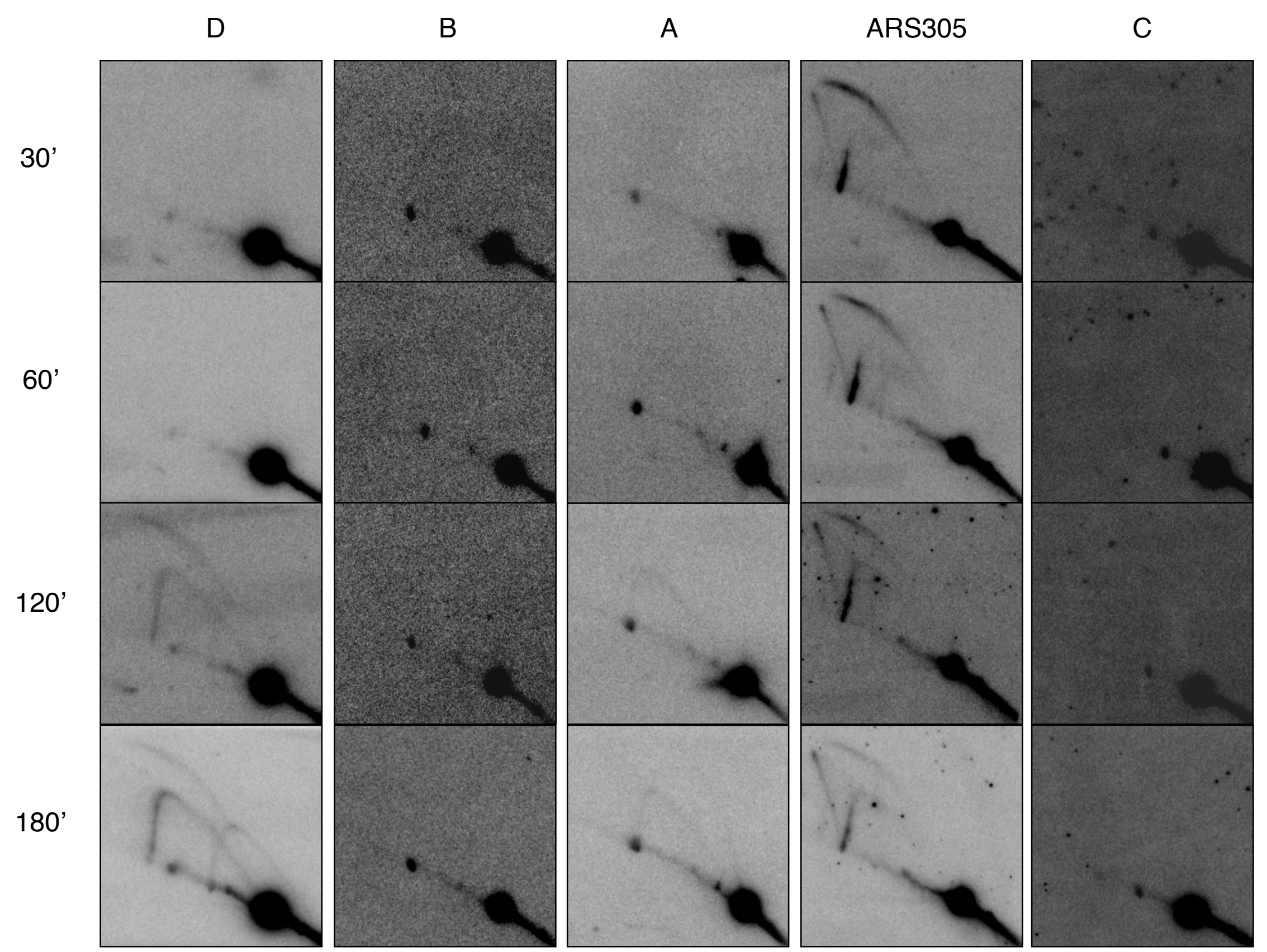

